\title{
Incidence and Seroprevalence of Avian Influenza in a Cohort of Backyard Poultry Growers, Egypt, August 2015-March 2019
}

\author{
Mokhtar R. Gomaa, ${ }^{1}$ Amira S. El Rifay, ${ }^{1}$ Dina Abu Zeid, Mona A. Elabd, Eman Elabd, \\ Ahmed Kandeil, Noura M. Abo Shama, Mina N. Kamel, Mohamed A. Marouf, Ahmed Barakat, \\ Samir Refaey, Amal Naguib, Pamela P. McKenzie, Richard J. Webby, Mohamed A. Ali, Ghazi Kayali
}

\begin{abstract}
Currently enzootic avian influenza H5N1, H9N2, and H5N8 viruses were introduced into poultry in Egypt in 2006, 2011, and 2016, respectively. Infections with H5N1 and H9N2 were reported among poultry-exposed humans. We followed 2,402 persons from households raising backyard poultry from 5 villages in Egypt during August 2015-March 2019. We collected demographic, exposure, and health condition data and annual serum samples from each participant and obtained swab samples from participants reporting influenza-like illness symptoms. We performed serologic and molecular analyses and detected 4 cases of infection with H5N1 and 3 cases with H9N2. We detected very low seroprevalence of $\mathrm{H} 5 \mathrm{~N} 1$ antibodies and no H5N8 antibodies among the cohort; up to $11 \%$ had $\mathrm{H} 9$ antibodies. None of the exposure, health status, or demographic variables were related to being seropositive. Our findings indicate that avian influenza remains a public health risk in Eqypt, but infections may go undetected because of their mild or asymptomatic nature.
\end{abstract}

For more than a decade, Egypt had endemic avian - influenza viruses (AIVs) that infected humans and caused substantial economic losses in the poultry industry (1). Co-circulation of highly pathogenic avian influenza (HPAI) H5N1 and H5N8 viruses and

Author affiliations: National Research Centre, Giza, Egypt (M.R. Gomaa, A.S. El Rifay, D. Abu Zeid, M.A. Elabd, E. Elabd,

A. Kandeil, N.M. Abo Shama, M.N. Kamel, M.A. Marouf, M.A. Ali); Ain Shams University, Cairo, Egypt (A. Barakat); Ministry of Health and Population, Cairo (S. Refaey, A. Naguib); St. Jude Children's Research Hospital, Memphis, Tennessee, USA (P.P. McKenzie, R.J. Webby); Human Link, Hazmieh, Lebanon (G. Kayali); University of Texas Health Sciences Center at Houston, Houston, Texas, USA (G. Kayali)

DOI: https://doi.org/10.3201/eid2609.200266 low pathogenic avian influenza (LPAI) H9N2 viruses among poultry was observed (2). The widespread circulation of various AIV subtypes in domestic poultry resulted in evolutionary changes that affected several virus characteristics (3-6).

According to the World Health Organization, the number of confirmed human H5N1 cases in Egypt is 359 , of which 120 were fatal (7). Those cases were detected by public health surveillance when the patients were admitted to hospitals with influenza-like illness (ILI) and had a history of poultry contact (8). However, this number is likely an underestimate because many patients might have mild symptoms or be asymptomatic and are less likely to seek medical care and therefore would not be tested or reported. Serologic testing might be a better tool in understanding the actual prevalence of disease because it can identify patients with mild or asymptomatic infections (9). A 3-year seroprevalence study showed that $\approx 2 \%$ of persons in Egypt exposed to poultry had been infected with H5N1 (10). This study demonstrated that the number of cases is underreported and that the casefatality rate is consequently overestimated. Another study conducted in Beheira Governorate, located between the cities of Alexandria and Cairo and through which substantial transport between those 2 urban centers occurs, showed that the seroprevalence rate for $\mathrm{H} 5$ antibodies was $4 \%$ in poultry workers $(11,12)$.

H9N2 viruses circulating in poultry in Egypt have human-like rather than avian-like receptor specificity (6). The clinical symptoms of H9N2 infection in humans are always mild, which complicates detection of human cases through hospital-based surveillance systems (13). Four laboratory-confirmed

${ }^{1}$ These authors contributed equally to this article. 
human cases of H9N2 infection were reported to the World Health Organization from Egypt during March 2015-April 2016. Seroprevalence of H9N2 antibodies in persons in Egypt exposed to poultry were $5.6 \%$ and $7.5 \%$ during the first 2 years of introduction of H9N2 in Egypt (10).

Since 2017, several H5N8 outbreaks of clade 2.3.4.4 (group B) have been detected in domestic poultry in several governorates in Egypt $(2,14)$. No human cases of H5N8 were reported in Egypt or elsewhere.

Serologic studies and hospital-based surveillance do not provide accurate estimates of incidence of avian influenza infections in exposed humans. Hence, we designed a household prospective cohort study to examine the incidence, human-to-human transmission, and prognosis of AIV infections among poultryexposed growers in Egypt.

\section{Methods}

\section{Study Design}

Details of the study design and protocol were previously published (15). In brief, households raising backyard poultry were selected from 5 villages in 4 Nile Delta governorates (Sharkiya, Gharbiya, Kafr El Sheikh, and Qalyubiya) and Fayyoum Governorate starting in August 2015. Baseline enrollment was completed in March 2017. Follow-up period 1 occurred April 2017-March 2018, and follow-up period 2 occurred April 2018-March 2019. All persons within the household who were $>2$ years of age were invited to participate. Household data pertaining to raising poultry was collected. Individual demographic, poultry exposure, and health condition data were collected. At the baseline and follow-up period 1, a serum sample was collected from each participant.

As of April 2017, study staff were visiting enrolled households on a weekly basis to check whether any study participant was reporting ILI symptoms. ILI was defined as having fever of $\geq 38^{\circ} \mathrm{C}$ as well as cough, sore throat, or both. The frequency of household visits was increased to twice per week with the start of the influenza season, which typically occurs October-March in Egypt. When a study participant was verified to have ILI symptoms, a serum sample was collected, and nasal and an oropharyngeal swab specimens were obtained and tested by reverse transcription PCR (RT-PCR) for influenza A infection. If any of the samples tested positive for influenza $\mathrm{A}$, the person was considered an index case-patient, and the study team obtained nasal and oropharyngeal swab specimens from the participant on days $3,6,9$, and 14 after the first swab day and a serum sample on day 14. Furthermore, all previously enrolled participants residing with the index case-patient were swabbed according to the same sampling schedule.

\section{Laboratory Methods}

Reverse-genetics avian influenza viruses (rg A/ chicken/Egypt/D10552B/2015 [clade 2.2.1.2 H5N1]) and (rgA/green-winged teal/Egypt/871/2016 [clade 2.3.4.4 H5N8] and A/chicken/Egypt/D10802C/2015 [G1-like H9N2]) were cultivated in 10 day-old, specific pathogen-free, embryonated chicken eggs and incubated for $48 \mathrm{~h}$ at $37^{\circ} \mathrm{C}$, then chilled at $4^{\circ} \mathrm{C}$ for $4 \mathrm{~h}$. The allantoic fluid was harvested, clarified, tested for the hemagglutinin (HA) gene and 50\% tissue culture infective dose titer, and then frozen at $-80^{\circ} \mathrm{C}$ until use.

Collected blood samples were kept on ice until they reached the laboratory on the same day. Serum was separated by centrifugation at $1,000 \times g$, aliquoted, and frozen at $-20^{\circ} \mathrm{C}$ until use. Virus microneutralization assay was performed to test all collected serum samples for antibodies against the 3 AIVs (16). Chicken hyperimmune serum samples previously produced individually against the 3 viruses were used as positive controls and included in each assay. Neutralization capacity for each enrolled participant's serum sample of infected MDCK cells was tested for hemagglutination activity of viruses by using $0.5 \%$ chicken red blood cells (RBCs) in an HA gene assay. The absence of hemagglutination was considered a positive test result for antibodies to the virus. Virus microneutralization assay positivity was considered at an endpoint titer of $\geq 1: 80$. Seasonal influenza A/Brisbane/10/07(H3N2) and pandemic A/ California/04/09(H1N1) viruses were used to determine seroprevalence antibodies against both viruses by a hemagglutination inhibition (HI) assay, using $0.5 \%$ turkey RBCs (17).

\section{Molecular Detection}

Nasal and oropharyngeal swabs were subjected to viral RNA extraction by using the QIAamp Viral RNA Mini Kit (QIAGEN, https://www.qiagen.com), followed by detection of influenza $\mathrm{A}$ infection by $\mathrm{M}$ gene RT-PCR (17). Influenza A-positive samples were subtyped with RT-PCR using subtype-specific primers for HA gene subtyping (18). As soon as a participant had a positive $M$ gene RT-PCR result, they were informed and advised to seek medical care. Amplicons of the appropriate sizes of positive HA gene subtypes were subsequently gel-purified by using the QIAGEN Gel Extraction Kit and then delivered for sequencing at a sequencing facility in South Korea (Macrogen, 
https://www.macrogen.com). Sequences were assembled by using SeqMan Lasergene 7 (DNASTAR, https://www.dnastar.com). Sequence alignments were performed by using BioEdit version 7.0 (https:/ / www.biodeit.software.informer.com). The phylogenetic tree was constructed by using MEGA version 7 (https://www.megasoftware.net) by applying the neighbor-joining method with the Kimura 2-parameter substitution model and 1,000 bootstrap replicates.

\section{Statistical Analyses}

SPSS Stastistics 23 (IBM, https:/ / www.ibm.com) was used for statistical analyses. Statistical differences between proportions were tested by using the Pearson's $\chi^{2}$ test or Fisher exact test. The Student $t$-test was used to compare continuous variables. A $p$ value $\leq 0.05$ was considered statistically significant.

\section{Ethical Considerations}

This study was approved by the institutional review boards of Human Link and St. Jude Children's Research Hospital and by the Ethics Committee of the National Research Centre. Written informed consent was obtained from adults $\geq 18$ years of age. Informed assent and parental approval were obtained for participants 14-17 years of age. Oral assent and parental approval were obtained for participants 7-13 years of age. Parental approval was obtained for participants 2-7 years of age.

\section{Results}

A total of 2,402 participants were enrolled from 390 households in the 5 study sites (Appendix Table, https: / / wwwnc.cdc.gov/EID/article/26/9/200266-App1.pdf). The median number of participants per household was 5 (range 1-20). Various domestic mammals and poultry were raised by the households, most frequently chickens and ducks. Approximately one third of the households raised pigeons and geese, whereas $\approx 12 \%$ raised turkeys (Table 1 ). Table 2 shows the distribution of poultry-raising practices followed by participants. Approximately $17 \%$ of households reported raising poultry within the household, whereas $\approx 53 \%$ kept the poultry on the roof and $\approx 30 \%$ in a barn. Dead poultry was disposed of by burying, discarding in a closed trash bag, or burning by $44 \%$ of the respondents, whereas $56 \%$ either dumped the carcasses in the open trash or in small water canals. Approximately $38 \%$ said that they would consult a veterinarian when they noticed ill poultry, and $14 \%$ said that they would isolate the ill birds from the rest of the flock. Approximately 33\% of respondents said they would get rid of the sick bird while it was
Table 1. Animals raised by enrolled households in a study of avian influenza among backyard poultry growers, Egypt, August 2015-March 2019

\begin{tabular}{lcc}
\hline Animal & \% Households & Median no. animals (range) \\
\hline Chickens & 91.3 & $15(1-100)$ \\
Ducks & 83.6 & $10(1-700)$ \\
Pigeons & 34.4 & $10(1-100)$ \\
Geese & 27 & $4(1-20)$ \\
Donkeys & 25.9 & $1(1-3)$ \\
Buffaloes & 25.6 & $2(1-7)$ \\
Cows & 24.6 & $1(1-7)$ \\
Sheep & 15.3 & $1(1-30)$ \\
Goats & 12.1 & $2(1-30)$ \\
Turkeys & 11.7 & $14(1-15)$ \\
Dogs & 8.2 & $2(1-4)$ \\
Rabbits & 7.8 & $5(1-70)$ \\
Horses & 5.8 & $1(1-10)$ \\
Cats & 2.5 & $7(1-10)$ \\
Camels & 0.01 & $1(1-2)$ \\
\hline
\end{tabular}

alive, whereas $\approx 12 \%$ said they would slaughter and eat it. One third of the respondents reported using avian influenza vaccines for their poultry, but only $1 \%$ of those were able to determine that the vaccine was used against H5N1 influenza virus, whereas the rest did not know what the vaccine was used against. Vaccination was mostly performed by a veterinarian $(77 \%)$ or by a hired aid or a family member.

Demographic and health data of the participants are summarized in Table 3. Respondents' age ranged from 2 to 102 years. The mean age was 25 years, and the median age was 21 years. The distribution of enrolled participants by sex, age (adults versus children), and marital status (single versus other) was almost the same. Most participants were uneducated

Table 2. Poultry-raising practices reported by participants in a study of avian influenza among backyard poultry growers, Egypt, August 2015-March 2019

\begin{tabular}{lc}
\hline Characteristic & No. (\%) \\
\hline Where do you keep the poultry? & \\
On the roof & $1,267(52.7)$ \\
In a barn & $716(29.8)$ \\
Inside the house & $419(17.4)$ \\
\hline What do you do with poultry carcasses? & $255(10.6)$ \\
Bury & $728(30.3)$ \\
Place in a closed bag and throw in the trash & $83(3.5)$ \\
Burn & $652(27.1)$ \\
Throw in the trash without a bag & $684(28.5)$ \\
Throw in a water stream without a bag & \\
What do you do if you suspect sick poultry? & $81(3.4)$ \\
Nothing & $791(32.9)$ \\
Set loose away from the house & $909(37.8)$ \\
Seek veterinary advice & $332(13.8)$ \\
Quarantine away from the rest of the flock & $289(12.0)$ \\
Slaughter and consume the meat & \\
\hline Do you vaccinate poultry against avian influenza? & \\
Yes & $902(37.6)$ \\
No & $1,500(62.4)$ \\
\hline Who administers the vaccine? & $155(17.1)$ \\
Family member & $698(77.4)$ \\
Veterinarian & $49(5.4)$ \\
\hline Worker & \\
\hline
\end{tabular}


or received only a primary education (68\%), and $12 \%$ had a job as a skilled laborer or professional. Approximately $10 \%$ had chronic health problems, and $\approx 2 \%$ had long-term respiratory problems. Less than $10 \%$ reported currently using tobacco. Only 4 participants reported ever receiving the influenza vaccine.

The median number of days per week that the participants had direct contact with poultry was 6 days. The participants spent a median of 10 minutes per day in direct contact each time they came in direct exposure with the poultry. Table 4 summarizes the poultry exposure practices of the participants. More than $70 \%$ reported cleaning poultry cages or feeding poultry, whereas $30 \%$ reported not having any direct poultry exposure. Among those who had direct poultry exposure (cleaning or feeding), only $10 \%$ reported using a dedicated garment. Approxi-

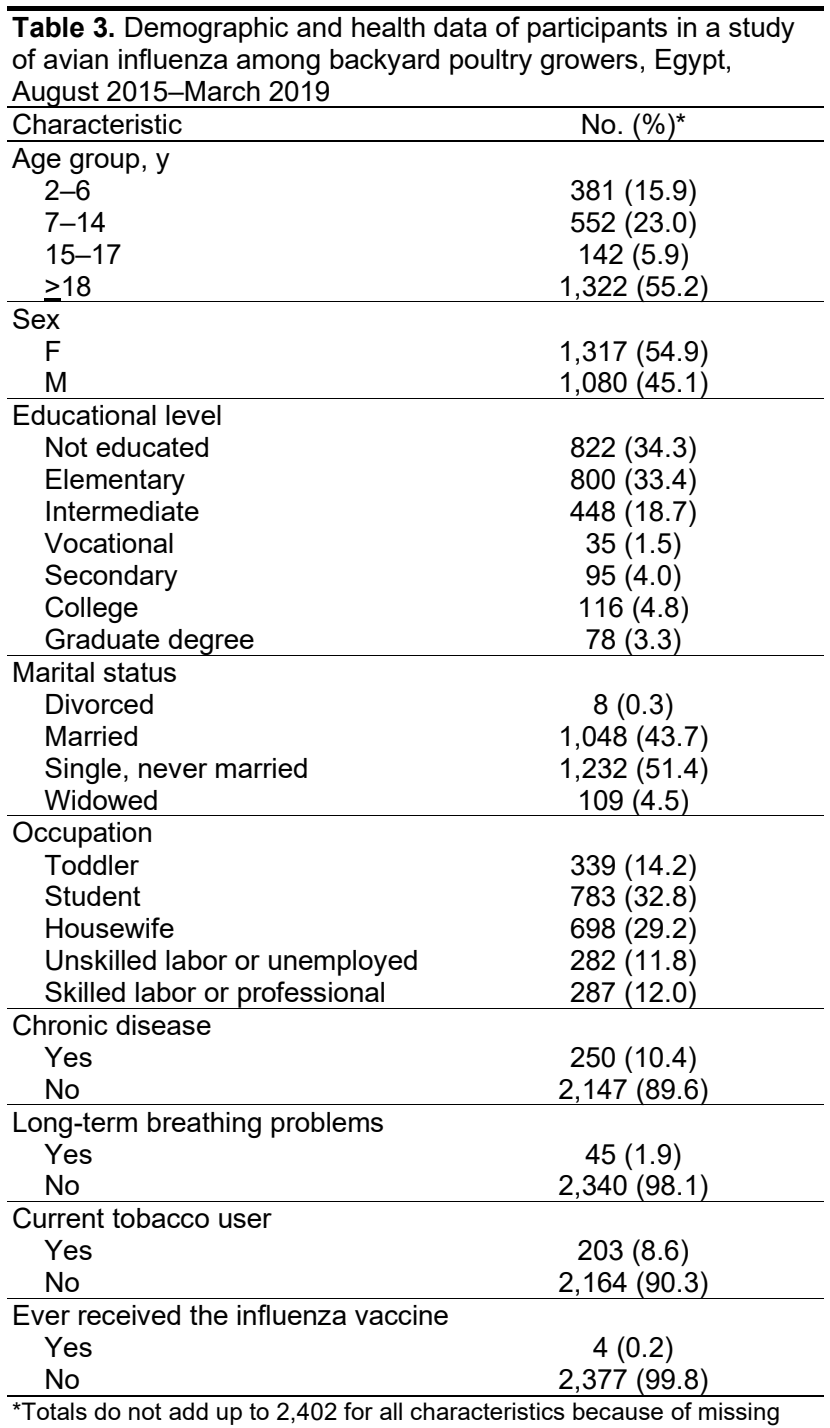

Totals do not add up to 2,402 for all characteristics because of missing data. mately one third of the participants reported slaughtering poultry. Slaughtered poultry were mostly kept in a dedicated barrel to bleed $(80 \%)$, but $20 \%$ of respondents left that to occur in the open. Most of the respondents cleaned the used utensils after slaughtering, mostly by using soap and water. Slaughter waste was disposed in closed bags and thrown into the trash ( $46 \%$ of respondents), thrown in open trash $(25 \%)$, or dumped into small canals $(29 \%)$.

Serologic findings at baseline and follow-up period 1 (2017-2018) are shown in Table 5. Serum samples were successfully collected from 2,397 persons at baseline and from 2,051 at follow-up period 1 . Seroprevalence of $\mathrm{H} 1 \mathrm{~N} 1$ antibodies was $\approx 30 \%$ and of H3N2 antibodies was $\approx 50 \%$. At baseline, $9(0.4 \%)$ participants had H5N1 antibodies. Four participants had a titer of 1:80, and 5 had a titer of 1:160. Of the 9 participants, 7 came from 2 adjacent homes. At follow-up period 1 , only $4(0.2 \%)$ participants were seropositive for H5N1 antibodies, 3 with 1:80 titers and 1 with a 1:160 titer. None of the participants who were seropositive at baseline remained seropositive at followup period 1. At baseline, 266 (11\%) participants had H9N2 antibodies. Of these, the 227 had 1:80 titers, 37 had 1:160 titers, and 2 had 1:320 titers. Household clusters of seropositive persons were observed for 223 participants, with cluster sizes ranging from 2 to 10 participants. At follow-up period 1, only $3(0.1 \%)$ participants had H9N2 antibodies. All participants had a 1:80 titer and were from the same household, and only 1 of these participants was positive at baseline with the same titer. No participants had H5N8 antibodies at baseline or follow-up period 1 .

During follow-up period 1, a total of 400 participants $(16.7 \%$ of the cohort) were confirmed to have ILI symptoms. Of these, 113 were positive for influenza A by RT-PCR (28\% of those with ILI and $4.7 \%$ of cohort overall). Four case-patients were subtyped as infected with $\mathrm{H} 5 \mathrm{~N} 1$ virus by RT-PCR and confirmed by sequencing. The incidence of $\mathrm{H} 5 \mathrm{~N} 1$ infection in this cohort of 2,402 persons was 17 cases/10,000 exposed persons. Phylogenetic analysis revealed that the viruses causing the infection were of clade 2.2.1.2, which are unique to and endemic in Egypt.

The first case was in a 5-year-old boy with exposure to poultry at the household and at a live bird market. Only the swabs obtained on day 1 of the illness were positive for H5N1. The serum sample titer obtained on day 1 was $<1: 10$, whereas a titer of 1:40 was detected on day 14 . The boy's symptoms included fever, cough, sore throat, myalgia, malaise, headache, runny nose, and diarrhea. Fever persisted for 4 days; cough and sore throat continued to occur throughout 
the 14-day follow-up period. No household contacts showed symptoms, virus shedding, or seroconversion.

Case 2 was in an 11-year-old girl with direct contact with chickens and ducks. Only the swabs obtained on day 1 of the illness were positive for H5N1. The girl's serum sample titers were $<1: 10$. Symptoms included fever, cough, sore throat, malaise, headache, and runny nose. Fever and sore throat persisted for 2 days; all other symptoms cleared by the fourth day. No household contacts showed symptoms, virus shedding, or seroconversion.

Case 3 was in a 5-year-old boy with direct contact with chickens and ducks. Swabs continued to be positive up to day 9 of sampling. The boy's serum sample titers were $<1: 10$. Symptoms included fever, cough, sore throat, malaise, headache, diarrhea, myalgia, and runny nose. Fever and cough persisted until day 9; all other symptoms were clear by the fourth day. No household contacts showed symptoms, virus shedding, or seroconversion.

Case 4 was in a 27-year-old woman who had direct contact with chickens and ducks. Swabs continued to be positive up to day 9 of sampling. The woman's serum sample titers were $<1: 10$. Symptoms included fever, cough, sore throat, malaise, headache, myalgia, and runny nose. Sore throat and cough persisted until day 12; all other symptoms were clear by the fourth day. No household contacts showed symptoms, virus shedding, or seroconversion.

During follow-up period 2, a total of 2,189 participants remained in the study, compared with 2,402 who participated in follow-up period 1. Of these, $740(33.8 \%)$ participants were confirmed to have ILI symptoms, of whom 158 were positive for influenza A by RT-PCR (21\% of those with ILI and $7.2 \%$ of the cohort overall). Four case-patients were infected with H9N2 and 1 with H5N1 virus according to RT-PCR results, which were confirmed by sequencing. The incidence of H9N2 infection was 18 cases $/ 10,000$ exposed persons. Incidence of H5N1 was 5 cases $/ 10,000$ exposed persons. Phylogenetic analysis revealed that the H9N2 viruses causing the infection were G1-like viruses (Appendix Figure 1), similar to viruses circulating in poultry in Egypt, whereas the H5N1 viruses were of clade 2.2.1.2 (Appendix Figure 2).

The H5N1 case was in a 10-year-old girl with direct contact with chickens and ducks. Swabs were

\begin{tabular}{|c|c|}
\hline Characteristic & No. $(\%)^{*}$ \\
\hline \multicolumn{2}{|l|}{ What is the type of exposure you have with poultry? } \\
\hline Cleaning area where poultry is kept & $671(28.0)$ \\
\hline Feeding poultry & $366(15.3)$ \\
\hline Only walk through area where poultry is kept & $300(12.5)$ \\
\hline Play in area where poultry is kept & $347(14.5)$ \\
\hline \multicolumn{2}{|l|}{ Do you usually slaughter poultry? } \\
\hline Yes & $694(31.3)$ \\
\hline No & $1,526(68.7)$ \\
\hline \multicolumn{2}{|l|}{ Use of personal protective equipment while slaughtering poultry } \\
\hline Yes (apron, boots, dedicated garment, face mask, gloves) & $75(10.8)$ \\
\hline No & $619(89.2)$ \\
\hline \multicolumn{2}{|l|}{ Where is slaughtered poultry kept to bleed? } \\
\hline In a dedicated barrel & $553(79.6)$ \\
\hline In a sink & $45(6.5)$ \\
\hline On the floor inside the house & $49(7.1)$ \\
\hline On the floor outside the house & $47(6.8)$ \\
\hline \multicolumn{2}{|l|}{ Are tools cleaned after slaughtering? } \\
\hline Yes & $684(98.6)$ \\
\hline No & $10(1.4)$ \\
\hline \multicolumn{2}{|l|}{ How are tools cleaned? } \\
\hline Water only & $103(14.8)$ \\
\hline Soap and water & $539(77.7)$ \\
\hline Disinfectant & $52(7.5)$ \\
\hline \multicolumn{2}{|l|}{ Use of personal protective equipment while defeathering poultry } \\
\hline Yes (apron, boots, dedicated garment, face mask, gloves) & $54(7.8)$ \\
\hline No & $640(92.2)$ \\
\hline \multicolumn{2}{|l|}{ Method of disposing slaughtering waste } \\
\hline Place in a closed bag and throw in the trash & $299(45.7)$ \\
\hline Feed to other animals & $1(0.2)$ \\
\hline Throw in the trash without a bag & $163(24.9)$ \\
\hline Throw in a water stream without a bag & $191(29.2)$ \\
\hline
\end{tabular}


Table 5. Seroprevalence of antibodies against influenza A virus subtypes H5N1, H5N8, H9N2, H1N1, and H3N2 in participants in a study of avian influenza among backyard poultry growers, Egypt, August 2015-March 2019

\begin{tabular}{lc}
\hline Period and influenza virus subtype & No. $(\%)$ \\
\hline Baseline period, August 2015-March 2017 & \\
H5N1 positive & $9(0.4)$ \\
H5N1 negative & $2,388(99.6)$ \\
H5N8 positive & 0 \\
H5N8 negative & $2,397(100.0)$ \\
H9N2 positive & $266(11.1)$ \\
H9N2 negative & $2,131(88.9)$ \\
H1N1 positive & $656(29.5)$ \\
H1N1 negative & $1,569(70.5)$ \\
H3N2 positive & $1,115(49.3)$ \\
H3N2 negative & $1,148(50.7)$ \\
\hline Follow-up period 1, April 2017-March 2018 & \\
H5N1 positive & $4(0.2)$ \\
H5N1 negative & $2,046(99.8)$ \\
H5N8 positive & 0 \\
H5N8 negative & $2,046(100.0)$ \\
H9N2 positive & $3(0.1)$ \\
H9N2 negative & $2,043(99.9)$ \\
H1N1 positive & $612(29.8)$ \\
H1N1 negative & $1,439(70.2)$ \\
H3N2 positive & $1,034(50.5)$ \\
H3N2 negative & $1,015(49.5)$ \\
\hline${ }^{*}$ Totals do not add up to 2,402 at baseline period or 2,189 at follow-up \\
period 1 because of missed serum sample collection or insufficient sample \\
volume. \\
\hline
\end{tabular}

positive on day 1 only. The girl's serum sample titers were $<1: 10$. Symptoms included fever, cough, sore throat, and myalgia. Sore throat and cough persisted until day 12; all other symptoms were clear by the fourth day. Two household contacts showed symptoms but were negative for $\mathrm{H} 5$, virus shedding, or seroconversion.

The first H9N2 case was in a 64-year-old woman with direct contact with chickens and ducks. Swabs were positive up to day 5 of sampling. The woman's serum sample titers were $<1: 10$. Symptoms included fever, cough, sore throat, diarrhea, runny nose, and myalgia, all of which persisted up to 8 days. No household contacts showed symptoms, virus shedding, or seroconversion.

The second H9N2 case was in an 8-year-old girl with direct contact with chickens and ducks. Swabs were positive up to day 5 of sampling. The girl's serum sample titers were $<1: 10$. Symptoms included fever, cough, sore throat, runny nose, and myalgia, all of which persisted up to 5 days except for coughing, which continued for 3 more days. No household contacts showed symptoms, virus shedding, or seroconversion.

The third H9N2 case was in a 15-year-old boy with direct contact with chickens and ducks. Swabs were positive up to day 5 of sampling. The boy's serum sample titers were $<1: 10$. Symptoms included fever, cough, sore throat, runny nose, and myalgia, all of which persisted up to 10 days. No household contacts showed symptoms, virus shedding, or seroconversion.

The fourth H9N2 case was in a 13-year-old girl. This case was detected 3 days after follow-up of another H3N2-positive case-patient in her household. Of the 5 members in her household, 4 had low-grade fever. H9N2 was detected in nasal and oral swab specimens from the case-patient, and the remaining household contacts were either negative or had H3N2 infection. The case-patient had low-grade fever, sore throat, runny nose, malaise, and breathing difficulty up to 6 days after detection.

\section{Discussion}

We conducted a large prospective household cohort study of AIV infections among persons exposed to backyard poultry in Egypt. Our study design solved several problems that were noted by other similar studies $(19,20)$. The larger sample size provided enough statistical power to detect the rare event of detecting active infection with AIVs. Following the households closely enabled us to detect those cases and document case-patients' shedding, symptoms, and seroconversion. This approach also enabled us to verify whether human-to-human transmission was occurring.

Our epidemiologic findings confirm that backyard poultry raising practices have low to no biosecurity measures; these practices included keeping poultry within the household, disposing dead poultry in the open trash or water streams, and letting ill poultry loose. Growers did not frequently use personal protective equipment while exposed to poultry. Few of them reported using dedicated garments while tending to poultry, even though this measure was a main recommendation of previous educational campaigns. Similarly, only $10 \%$ of participants who reported slaughtering poultry (the riskiest behavior because of the aerosols generated [21]) used any personal protective equipment. Reviewing, revising, and updating health education and awareness campaigns based on scientific evidence might assist in decreasing the incidence of infection with AIVs in Egypt (21).

Very low seroprevalence of H5N1 antibodies was detected, whereas up to $11 \%$ of the participants had $\mathrm{H} 9$ antibodies, possibly because during the study period $\mathrm{H} 5 \mathrm{~N} 1$ infection was rare in poultry but $\mathrm{H} 9 \mathrm{~N} 2 \mathrm{in}-$ fection was common (2). Another explanation for the low level of seroprevalence noted, especially against $\mathrm{H} 5 \mathrm{N1}$, is that some sampling was conducted over summer months, when avian influenza activity is low. Further explanation might include waning antibody titers or lack of seroconversion. 
None of the participants had H5N8 antibodies, even though these viruses are not uncommon in poultry in Egypt. In the United States, humans who were exposed to birds infected with clade 2.3.4.4 H5 viruses did not show any acute respiratory symptoms (22). Viruses of this clade might not be transmitting efficiently from birds to humans because they have limited capacity for replication and transmission in mammals and mammalian cell lines (23).

None of the exposure, health status, or demographic variables we collected were associated with being seropositive. This finding might indicate that being seropositive is related to factors not collected in this study, such as host genetic factors or other behaviors.

Our study had enough power to detect active infection with AIVs. Human infections with H5N1 and H9N2 but not H5N8 were detected. Egypt had previously reported human cases of $\mathrm{H} 5 \mathrm{~N} 1$ and H9N2 infection; human infection with $\mathrm{H} 5 \mathrm{~N} 8$ has not been reported. Incidence of infection with any avian influenza virus was 5-18 cases/10,000 poultry-exposed persons, meaning that the number of reported cases is much lower than the number of infections that actually occur. This occurrence can be explained by the fact that none of the case-patients we detected died or required hospitalization, which would make them easily missed by hospital- or clinic-based surveillance. Although the number of reported cases might be underestimated, the reported case-fatality rates are overestimated because of the mild and asymptomatic cases that were missed.

The reported symptoms were similar to symptoms of infection with seasonal influenza viruses. All case-patients had fever, cough, sore throat, and myalgia. Malaise and diarrhea occurred in a few cases. Most case-patients used over-the-counter antipyretic or anti-inflammatory drugs to treat their symptoms. Shedding duration ranged from 1 to 9 days, but no human-to-human transmission was detected, meaning that exposure to viruses that infected the poultry remains the source of human infection. Because of delays in confirming avian influenza in study participants, we were not able to obtain samples from poultry at the time when the participant was ill. Sampling poultry at the same time of sampling humans would have provided better information on how poultry infections correlate with human infections. The exact routes of transmission from poultry to humans, whether direct contact or aerosol, remain to be determined. Observing or documenting behaviors through surveys does not pinpoint transmission routes; hence, future studies should consider measuring individual exposure by using virologic methods, such as determining presence of virus on surfaces or in the air to which humans are exposed, especially in household settings, similar to what has been done in live bird market settings (24-28).

Serologic and virologic findings were not correlated, especially for H9N2 infections. In follow-up period 1, no cases of H9N2 were detected, yet $11 \%$ of the participants had antibodies. In follow-up period 2 , cases were detected, but seroprevalence was almost negligible. These findings indicate that relying on serologic tests alone to estimate disease incidence might be misleading, given that many case-patients do not seroconvert, as we found in this study.

In conclusion, backyard poultry growers in Egypt continue to be infected with AIVs that are enzootic in their poultry. To eliminate human cases, poultry infections should be controlled and growers' awareness increased to decrease the adverse effects of substandard poultry-raising practices.

This work was funded by the National Institute of Allergy and Infectious Diseases, National Institutes of Health, US Department of Health and Human Services (contract no. HHSN272201400006C), and supported by an internal fund from Human Link.

\section{About the Author}

Mr. Gomaa is a PhD student in microbiology and Dr. El Rifay is an assistant professor at the National Research Centre in Cairo. Their interests are studying the incidence and prevalence of avian influenza and other emerging zoonotic viruses. They are also interested in conducting surveillance for these viruses at the humananimal interface.

\section{References}

1. Aly MM, Arafa A, Hassan MK. Epidemiological findings of outbreaks of disease caused by highly pathogenic H5N1 avian influenza virus in poultry in Egypt during 2006. Avian Dis. 2008;52:269-77. https://doi.org/10.1637/ 8166-103007-Reg.1

2. Kandeil A, Hicks JT, Young SG, El Taweel AN, Kayed AS, Moatasim Y, et al. Active surveillance and genetic evolution of avian influenza viruses in Egypt, 2016-2018. Emerg Microbes Infect. 2019;8:1370-82. https:// doi.org/10.1080/ 22221751.2019.1663712

3. Cattoli G, Milani A, Temperton N, Zecchin B, Buratin A, Molesti E, et al. Antigenic drift in H5N1 avian influenza virus in poultry is driven by mutations in major antigenic sites of the hemagglutinin molecule analogous to those for human influenza virus. J Virol. 2011;85:8718-24. https://doi.org/10.1128/JVI.02403-10

4. El-Shesheny R, Kandeil A, Bagato O, Maatouq AM, Moatasim Y, Rubrum A, et al. Molecular characterization of avian influenza H5N1 virus in Egypt and the emergence 
of a novel endemic subclade. J Gen Virol. 2014;95:1444-63. https:/ / doi.org/10.1099/vir.0.063495-0

5. Kandeil A, El-Shesheny R, Maatouq AM, Moatasim Y, Shehata MM, Bagato $\mathrm{O}$, et al. Genetic and antigenic evolution of H9N2 avian influenza viruses circulating in Egypt between 2011 and 2013. Arch Virol. 2014;159:2861-76. https://doi.org/10.1007/s00705-014-2118-z

6. Kandeil A, El-Shesheny R, Maatouq A, Moatasim Y, Cai Z, McKenzie P, et al. Novel reassortant H9N2 viruses in pigeons and evidence for antigenic diversity of H9N2 viruses isolated from quails in Egypt. J Gen Virol. 2017;98:548-62. https://doi.org/10.1099/jgv.0.000657

7. World Health Organization. Cumulative number of confirmed human cases for avian influenza A(H5N1) reported to WHO, 2003-2019. 2019 [cited 2020 Feb 6]. https://www.who.int/influenza/human_animal_ interface/2019_11_25_tableH5N1.pdf

8. Refaey S, Azziz-Baumgartner E, Amin MM, Fahim M, Roguski K, Elaziz HA, et al. Increased number of human cases of influenza virus A(H5N1) infection, Egypt, 2014-15. Emerg Infect Dis. 2015;21:2171-3. https:/ / doi.org/10.3201/ eid2112.150885

9. Zhang AJX, To KKW, Tse H, Chan K-H, Guo K-Y, Li C, et al. High incidence of severe influenza among individuals over 50 years of age. Clin Vaccine Immunol. 2011;18:1918-24. https://doi.org/10.1128/CVI.05357-11

10. Gomaa MR, Kayed AS, Elabd MA, Zeid DA, Zaki SA, El Rifay AS, et al. Avian influenza A(H5N1) and A(H9N2) seroprevalence and risk factors for infection among Egyptians: a prospective, controlled seroepidemiological study. J Infect Dis. 2015;211:1399-407. https:/ / doi.org/ 10.1093/infdis/jiu529

11. Samaha H, Ibrahim MS, Ayoub M, Shaaban SI. Seroepidemiology of avian influenza viruses $\mathrm{H} 5$ and H9 in Beheira Governorate. Alex J Vet Sci. 2015;44:86-92. https://doi.org/10.5455/ajvs.161061

12. Young SG, Kitchen A, Kayali G, Carrel M. Unlocking pandemic potential: prevalence and spatial patterns of key substitutions in avian influenza H5N1 in Egyptian isolates. BMC Infect Dis. 2018;18:314. https:/ / doi.org/10.1186/ s12879-018-3222-6

13. Pusch EA, Suarez DL. The multifaceted zoonotic risk of H9N2 avian influenza. Vet Sci. 2018;5:E82. https:/ / doi.org/ $10.3390 /$ vetsci5040082

14. World Organization for Animal Health (OIE). Update on avian influenza in animals 2017 [cited 2020 Feb 6]. https:/ / www.oie.int/en/animal-health-in-the-world/ update-on-avian-influenza/2017

15. El Rifay AS, Elabd MA, Abu Zeid D, Gomaa MR, Tang L, McKenzie PP, et al. Household transmission of zoonotic influenza viruses in a cohort of Egyptian poultry growers. JMIR Res Protoc. 2015;4:e74. https://doi.org/10.2196/ resprot. 4331

16. World Health Organization. Serological diagnosis of influenza by microneutralization assay. 2010 [cited 2020 Feb 6]. https:/ / www.who.int/influenza/gisrs_laboratory/2010_12_06_serological_diagnosis_of_influenza_by_ microneutralization_assay.pdf

17. World Health Organization. WHO manual on animal influenza diagnosis and surveillance. 2002 [cited 2020 Feb 6]. https://www.who.int/csr/resources/publications/ influenza/whocdscsrncs20025rev.pdf
18. Lee MS, Chang PC, Shien JH, Cheng MC, Shieh HK. Identification and subtyping of avian influenza viruses by reverse transcription-PCR. J Virol Methods. 2001;97:13-22. https:/ / doi.org/10.1016/S0166-0934(01)00301-9

19. Khurelbaatar N, Krueger WS, Heil GL, Darmaa B, Ulziimaa D, Tserennorov D, et al. Little evidence of avian or equine influenza virus infection among a cohort of Mongolian adults with animal exposures, 2010-2011. PLoS One. 2014;9:e85616. https:// doi.org/10.1371/journal. pone. 0085616

20. Krueger WS, Khuntirat B, Yoon IK, Blair PJ, Chittagarnpitch M, Putnam SD, et al. Prospective study of avian influenza virus infections among rural Thai villagers. PLoS One. 2013;8:e72196. https:/ / doi.org/10.1371/ journal.pone.0072196

21. Bertran K, Clark A, Swayne DE. Mitigation strategies to reduce the generation and transmission of airborne highly pathogenic avian influenza virus particles during processing of infected poultry. Int J Hyg Environ Health. 2018;221:893900. https:// doi.org/10.1016/j.ijheh.2018.05.013

22. Arriola CS, Nelson DI, Deliberto TJ, Blanton L, Kniss K, Levine MZ, et al.; H5 Investigation Group. Infection risk for persons exposed to highly pathogenic avian influenza A H5 virus-infected birds, United States, December 2014-March 2015. Emerg Infect Dis. 2015;21:2135-40. https://doi.org/10.3201/eid2112.150904

23. Kaplan BS, Russier M, Jeevan T, Marathe B, Govorkova EA, Russell CJ, et al. Novel highly pathogenic avian A(H5N2) and $\mathrm{A}(\mathrm{H} 5 \mathrm{~N} 8)$ influenza viruses of clade 2.3.4.4 from North America have limited capacity for replication and transmission in mammals. MSphere. 2016;1:e00003-00016. https://doi.org/10.1128/mSphere.00003-16

24. Bertran K, Balzli C, Kwon Y-K, Tumpey TM, Clark A, Swayne DE. Airborne transmission of highly pathogenic influenza virus during processing of infected poultry. Emerg Infect Dis. 2017;23:1806-14. https:/ / doi.org/10.3201/ eid2311.170672

25. Indriani R, Samaan G, Gultom A, Loth L, Irianti S, Adjid R, et al. Environmental sampling for avian influenza virus A (H5N1) in live-bird markets, Indonesia. Emerg Infect Dis. 2010;16:1889-95. https:/ / doi.org/10.3201/ eid1612.100402

26. Kang M, He J, Song T, Rutherford S, Wu J, Lin J, et al. Environmental sampling for avian influenza A(H7N9) in livepoultry markets in Guangdong, China. PLoS One. 2015; 10:e0126335. https://doi.org/10.1371/journal.pone.0126335

27. Zhou J, Wu J, Zeng X, Huang G, Zou L, Song Y, et al. Isolation of H5N6, H7N9 and H9N2 avian influenza A viruses from air sampled at live poultry markets in China, 2014 and 2015. Euro Surveill. 2016;21:30331. https://doi.org/10.2807/1560-7917.ES.2016.21.35.30331

28. Wu Y, Lin J, Yang S, Xie Y, Wang M, Chen X, et al. The molecular characteristics of avian influenza viruses (H9N2) derived from air samples in live poultry markets. Infect Genet Evol. 2018;60:191-6. https:/ / doi.org/10.1016/ j.meegid.2018.01.009

Address for correspondence: Ghazi Kayali, Camelia 2 Building, Said Freiha St, Hazmieh, Baabda, Lebanon; email: ghazi@human-link.org; Mohamed A. Ali, El Buhouth St, Dokki, Giza 12311, Egypt; email: mohamed.ali@human-link.org 